\title{
Macronutrient Substitutes and Weight-reduction Practices of Obese, Dieting, and Eating- disordered Women
}

\author{
ADAM DREWNOWSKI ${ }^{a}$ \\ Human Nutrition Program \\ University of Michigan School of Public Health \\ Ann Arbor, Michigan 48109-2029
}

One in three adult Americans is reported to be obese. Data from the 1989-91 National Health and Nutrition Examination Survey (NHANES III) place the prevalence of obesity at 33\%.' This represents a sharp increase from the 1976-80 NHANES II survey, which found that $24.4 \%$ of men and $26.7 \%$ of women were obese. ${ }^{2}$ Obesity was defined by the 85 th percentile cutpoint of $\mathrm{BMI}$ values $\left(\mathrm{BMI}=\mathrm{wt} / \mathrm{ht}^{2}\right)$ for a reference population in the third decade of life. ${ }^{2}$ According to some reports, the prevalence of obesity has increased most rapidly among children, teenagers, minorities, and newly immigrant ethnic groups. ${ }^{3,4}$ Adolescent women, in particular, showed the greatest increase in both energy intakes and body weights ${ }^{5}$ and appear to be the population at most risk.

Dieting to lose weight is a relatively common behavior, particularly among women. Most women, regardless of their body weight, wish to be thinner than they are. ${ }^{6}$ However, the precise nature of weight management practices can be difficult to establish, partly because of differing definitions of the word "diet." Survey studies that define dieting as restricting calories for the purpose of losing weight suggest that two out of five adult women are dieting at any one time. ${ }^{6}$ Lifetime prevalence of dieting to lose weight is, of course, much higher, and it is estimated that $\mathbf{8 0}$ or $90 \%$ of the female population have dieted at some point in their lives. ${ }^{78}$ Psychologists and social scientists have noted that dieting to lose weight has become a normative behavior among young women, even among those women who are not overweight or obese. ${ }^{9}$

The management of body weight is a major societal preoccupation and a multibillion dollar industry. Studies of weight management practices of overweight men and women suggest that reducing the amount of sugar and fat in the diet is the most common option by far. ${ }^{7,10}$ Most dieters, whether male or female, have at some point used foods containing macronutrient substitutes for weight control. Such foods are likely to contain intense sweeteners, fat replacement products, or both. Though not intended as appetite suppressants, foods containing macronutrient substitutes help to

${ }^{a}$ Address correspondence to Adam Drewnowski, Human Nutrition Program, School of Public Health M-5170, 1420 Washington Heights, Ann Arbor, MI 48109-2029. Tel: (313) 647-0208; fax: (313) 764-5233; e-mail: adamdrew@umich.edu. 
maintain the variety and the diversity of energy-restricted diets. ${ }^{10}$ The effectiveness of foods containing macronutrient substitutes in the management of body weight is a topic of both clinical and public health interest.

\section{WEIGHT MANAGEMENT PRACTICES}

Not all attempts at weight control are benign. Dieting behaviors are distributed along a continuum that ranges from complete lack of concern with body weight to pathological dieting and eating disorders. " Among scales and measures designed to assess the degree of concern with dieting and the type of efforts at weight control are the restraint scale, ${ }^{9}$ the eating pathology scale, ${ }^{11}$ the dieting severity scale, ${ }^{12}$ and numerous questionnaires that deal with binge eating and other symptoms of eating disorders. ${ }^{13.14}$ Clinically significant eating disorders, anorexia and bulimia nervosa, are generally regarded as the pathological extreme of a broader continuum of dieting behaviors. " Epidemiological studies have estimated the prevalence of anorexia nervosa among teenage women at approximately $1 \% .{ }^{15}$ Bulimia nervosa, a disorder characterized by binge eating and vomiting, is reported to affect between 1 and 3\% of college-age women. ${ }^{16}$ The recently defined binge-eating disorder (BED), a proposed DSM IV diagnostic category, is characterized by compulsive binge eating that is not followed by purging. ${ }^{17}$ BED is reported to affect up to one-third of all obese women, especially those with early onset obesity and a high proportion of obese parents and siblings. Early age at onset and high familial risk are the best current indices of genetic obesity. ${ }^{18}$ It is worth noting that the literature on obesity, binge eating, and eating disorders contains numerous references to food "cravings" or food "addictions," generally involving those foods that are either sweet or rich in fat. ${ }^{19,20}$

Human obesities are currently viewed as the outcome of an interaction between genetic predisposition and exposure to environmental variables, including diet. Much of recent research, conducted with animal models, has emphasized the genetic nature of obesity in both humans and rats. The search for the "obese" genotype has led to remarkable discoveries in molecular genetics. ${ }^{21}$ However, the heritable component may not be body weight per se, but a predisposition to the obese state, and it is wellknown that gene expression is modified by nutrients. Linking candidate genes with excess body fat, the common physiological end point for obesity, tells us nothing about the intervening mechanisms that may have led to gene expression in the first place. The search for an obese phenotype, that is, the outcome of the interaction between genetics and the environment, is likely to provide better clues regarding the development of obesity in humans. However, few studies have explored the potential impact of genetic factors on food selection, or examined the interaction between genetic predisposition to obesity and the dietary environment. Given recent evidence that the appetite for fats may carry an inherited component, ${ }^{22}$ one strategy for identifying behavioral manifestations of the obese phenotype might be to study human preferences for high-fat foods.

The contribution of sugar and fat intakes to the development of human obesity is a topic of immense theoretical and practical interest. The typical American diet is largely composed of these two ingredients, deriving $22 \%$ of energy from simple sugars, both natural and added, and $34-37 \%$ of energy from fats. ${ }^{23,24}$ It has long 
been a common belief that obesity was chiefly caused by lack of willpower and overconsumption of good tasting foods. ${ }^{25}$ Recent advances in medical research now show that human obesities represent a more complex physiological and metabolic disorder of multiple origin. . 21,22 Genetic predisposition, lifestyle factors, and individual food choices contribute in varying degrees to the expression of the obese state. The development of obesity is influenced by familial risk and can be delayed or modified by changes in energy intakes, physical activity, and energy expendure. The degree of overweight is modified further by dietary factors, such as the energy density or the fat content of the habitual diet. ${ }^{26}$

\section{SWEET TOOTH VERSUS FAT TOOTH}

Both obesity and the BED have now been linked to an increased pleasure response to dietary sugars and fats. Taste-related behaviors of obese and dieting women have recently become a focus of renewed research attention. Generally, the pleasure or hedonic response function to sweet stimuli follows an inverted- $U$ shape. ${ }^{27}$ Preference ratings for sucrose solutions in water increase up to a certain concentration of sucrose (usually $8-10 \% \mathrm{wt} / \mathrm{v}$ ) and then decline as the solution is perceived as sweet and therefore less pleasant. Only children show no hedonic "breakpoint" for sweet, selecting intensely sweet stimuli that often prove unpleasant to adults. ${ }^{27}$

Early research on obesity and taste preferences was largely limited to studies of sugar solutions in water. ${ }^{27}$ Following some disagreements as to whether obese women liked or disliked sweet stimuli, most researchers came to the conclusion that there was no single "obese" response to sweet taste. ${ }^{27}$ Individual differences in hedonic response profiles were so great as to outweigh any obese/normal differences. ${ }^{28,29}$ No obese response profile to sweetness was ever obeserved, and no direct connection was found between taste preferences for sweetness and body weight. Large-scale consumer survey studies showed no link between body weight and reported preferences for sucrose in canned peaches, lemonade, or ice cream. ${ }^{30}$

Later studies focused on the role of dietary fat in determining food acceptance. The earliest studies, conducted with normal-weight students, both male and female, employed 20 sweetened mixtures of milk, cream, and sugar as the sensory stimuli of choice. ${ }^{31}$ The stimuli provided a wide range of fat $(0-52 \% \mathrm{wt} / \mathrm{wt})$ and sugar levels (0-20\% wt/wt), presented in an orthogonal design. Mixtures of cream (20\% fat) and sugar $(10 \% \mathrm{wt} / \mathrm{wt})$ were the most highly preferred. Higher ratings were obtained for stimuli containing $20 \%$ fat and $8-10 \%$ sugar than for unsweetened dairy products, or for intensely sweet solutions of sucrose in skim milk. ${ }^{31}$ This synergistic effect of sugar and fat mixtures was soon confirmed in other studies conducted with other types of sugar/fat mixtures. ${ }^{31-39}$ In most cases, the sensory pleasure response was highly interactive and was linked to the proportions of sugar and fat in the stimulus sample. Stimuli used in these studies included sweetened milk and cream, milk shakes, cream cheese, cake frostings, and ice cream. ${ }^{32-39}$ The studies focused almost exclusively on sweetened dairy products, inasmuch as ice cream, milk shakes, pastries, and cakes are often mentioned in the context of food cravings and eating binges in women. ${ }^{19}$ Studies on sensory preferences for sugar and fat in nonclinical samples of children, adolescents, and adults are summarized in TABLE 1. 


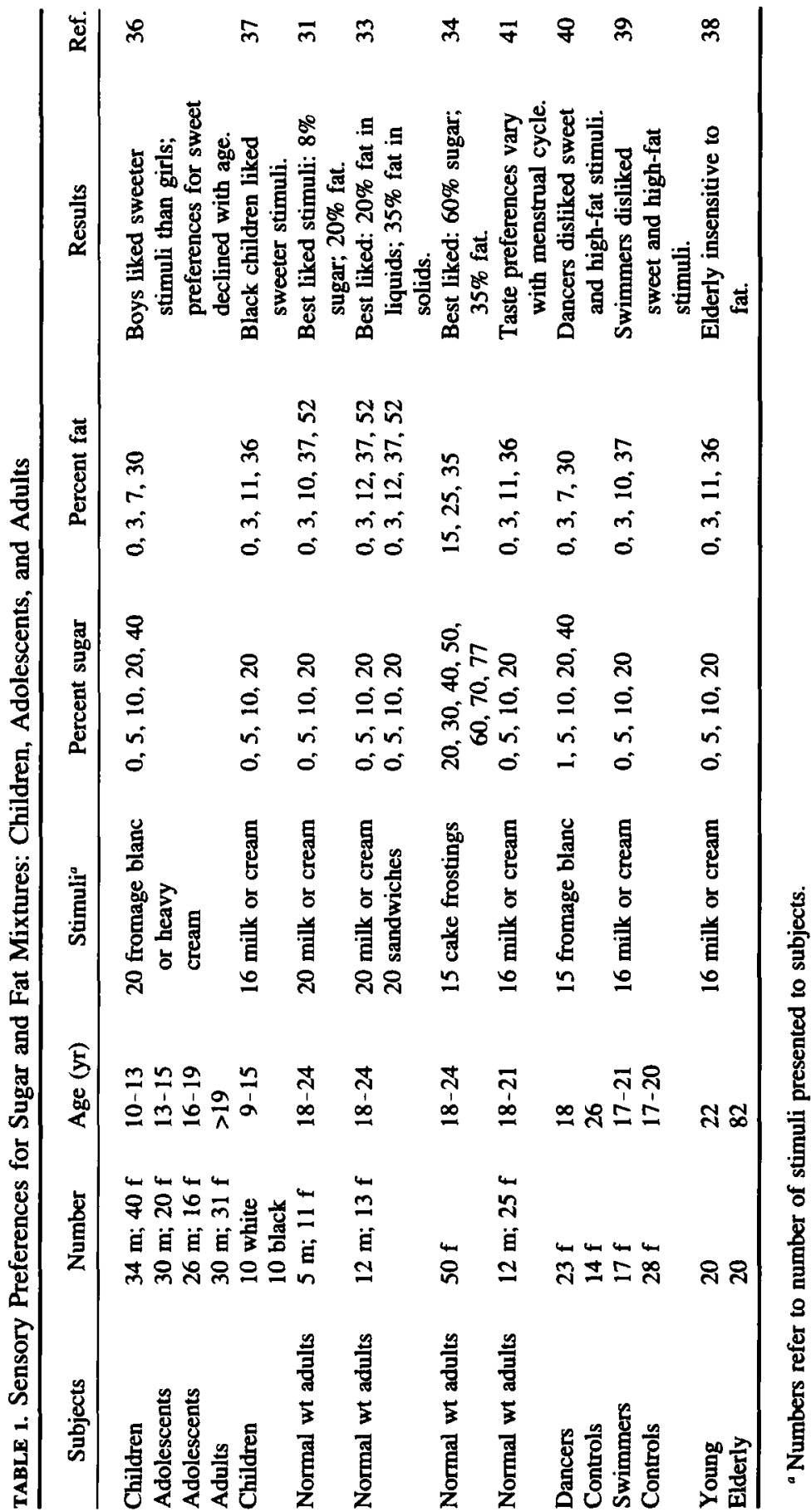


Reported preferences for sugar and fat were influenced by menstrual cycle and by dietary restraint. Dieting and weight-conscious women sometimes disliked all energy-dense foods and gave low ratings to stimuli containing either sugar or fat. As shown in TABLE 1, female varsity swimmers ${ }^{39}$ and ballet dancers ${ }^{40}$ disliked intensely sweet and fat-rich foods. One question is whether their responses were affected by concerns with weight and dieting and so were subject to cognitive bias.

Clinical studies on the acceptability of sugar/fat mixtures ${ }^{33,42-45}$ conducted with obese, dieting, and eating-disordered patients showed that dieting was generally associated with lower-reported preferences for sugar, fat, or both. Studies conducted with massively obese and formerly obese women showed that obese patients selected those stimuli that were relatively low in sugar but were rich in fat. Formerly obese subjects showed elevated preferences for intensely sweet and fat-rich foods. ${ }^{33}$ By contrast, women patients with a diagnosis of anorexia or bulimia nervosa sometimes liked sweet taste, when presented in a noningestive context but were invariably averse to the oral sensation of dietary fat. ${ }^{42-45}$ These studies are summarized in TABLE 2.

These studies demonstrated an inverse relationship between sensory preferences for fat and body weight. Generally, overweight and obese subjects selected high-fat stimuli, whereas lean subjects did not. ${ }^{33,42}$ Even so, the observed relationship between fat preferences and BMI was weak, accounting for no more than $4 \%$ of the variance. ${ }^{33,42}$ Significantly, obese individuals characterized by massive obesity and weight fluctuations gave higher ratings to fat-rich foods than equally obese individuals whose weights were more stable. ${ }^{36,45}$ Massive obesity and weight fluctuations are sometimes taken to be indices of a genetic predisposition to obesity, suggesting again that a selective appetite for fats in foods may be an expression of the obese phenotype.

\section{FOOD CHOICES IN OBESITY AND EATING DISORDERS}

In sensory studies, overweight and obese women showed elevated preferences for energy-dense foods, including some foods that were rich in fat. However, linking sensory studies with food intake data continues to challenge most investigators. Taste preference profiles have sometimes been linked with self-reported food preference data, most often obtained using questionnaires or checklists. By contrast, very few studies have managed to link sensory preferences with patterns of food intake. Though we often assume that sensory preferences influence dietary intakes, laboratory evidence on this point is often less firm than might be supposed.

One study ${ }^{46}$ examined preferences for different levels of fat in such foods as mashed potatoes, scrambled eggs, pudding, or tuna fish salad. There was no statistically significant link between liking for fat in foods and the amount of fat consumed. On the other hand, the researchers revealed a direct link between fat preferences and the subjects' own body fat. Consistent with previous results, ${ }^{33,42}$ preferences for dietary fats appeared to be linked to the degree of overweight.

A more recent study conducted with 3 to 5-year-old children suggests that preferences for fat in foods may carry an additional inherited component. In that study, ${ }^{47}$ preferences for fat-containing foods in a group of 18 children were successfully linked to the amount of fat consumed under laboratory conditions. Both measures were significantly linked to a measure of parental overweight, as determined by the 


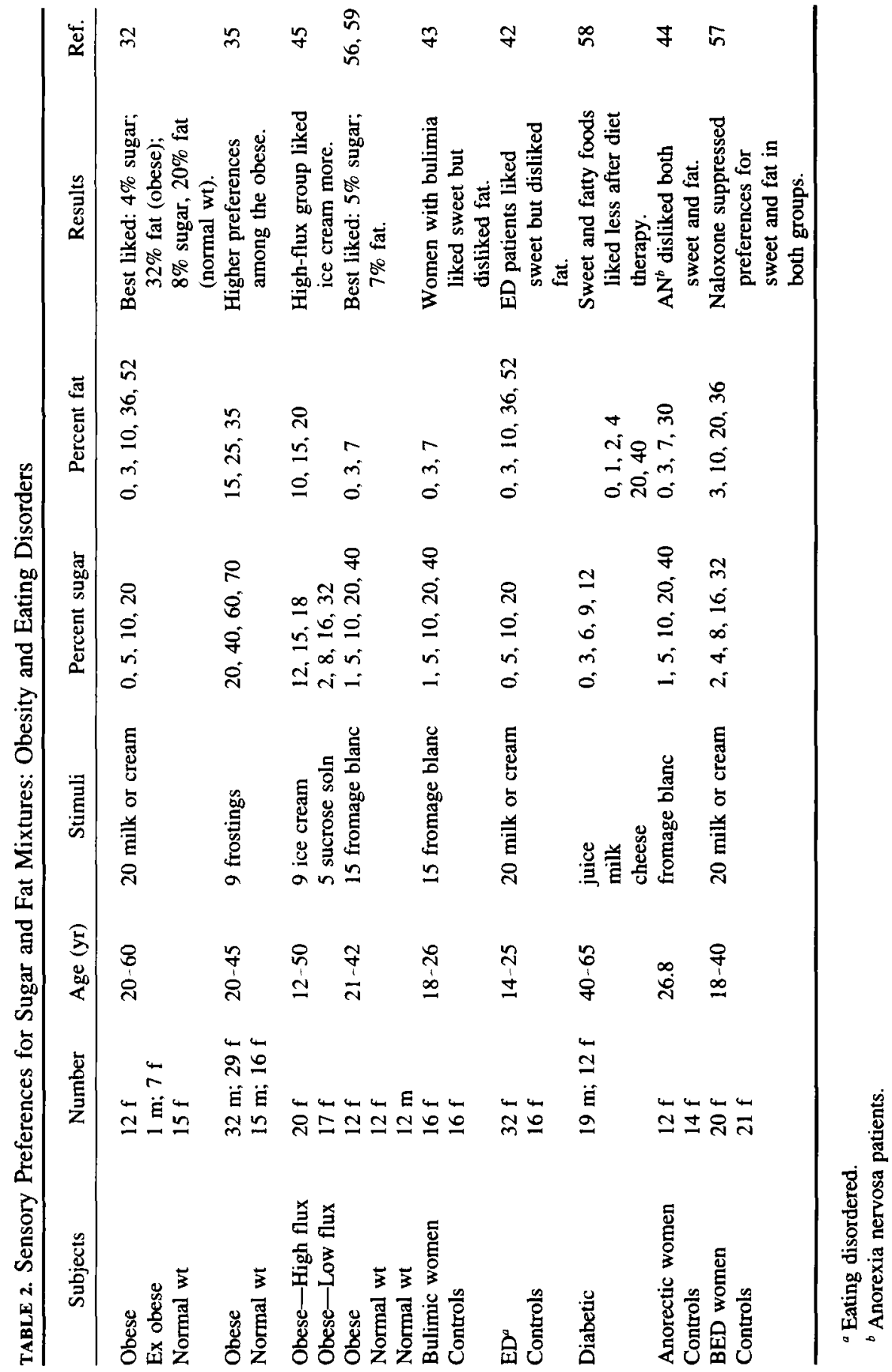


BMI $\left(B M I=\mathrm{kg} / \mathrm{m}^{2}\right)$. Although none of the parents in that study were overweight, studying fat preferences of lean children of obese parents would be a research project of exceptional interest. Fat preferences and fat consumption may represent a potential behavioral mechanism for the expression of familial obesity.

Other studies have examined food preference profiles as a function of sex and body weight. In a large study of U.S. Army personnel, Meiselman et al..$^{48}$ showed that overweight people selected red meat dishes rather than desserts. A study of several hundred obese patients ${ }^{49}$ confirmed that self-reported food preferences of obese males typically included steaks and roasts, hamburgers, french fries, pizza, and ice cream. By contrast, obese women tended to list bread, cake, cookies, ice cream, chocolate, pies, and other desserts. In other words, obese men tended to prefer protein/fat mixtures (i.e., meats), whereas obese women listed carbohydrate/ fat mixtures, notably those that were sweet. Although food preferences of obese women have been characterized as "carbohydrate cravings," preferences for fat, sugar, or both often seem closer to the mark.

Linking food preferences with food intake data poses a challenge to the investigator. Although dietary intake assessments have often failed to link obesity with excess energy intakes, the main problem may have been underreporting and bias. Studies using the doubly labeled water technique to measure energy expenditure showed conclusively that obese subjects had elevated resting energy expenditure values and probably consumed more calories than did lean controls..$^{50}$ Both clinical and epidemiological studies have also linked obesity with excessive consumption of dietary fat. In some studies, percent body fat was linked to percentage of fat calories in the habitual diet or with sensory preferences for fat in foods. ${ }^{46}$ In other studies, obesity was linked to an elevated proportion of fat in the diet and lower values of the carbohydrate-to-fat ratio. ${ }^{26}$

\section{MACRONUTRIENT SUBSTITUTES}

Has the availability of low-energy foods diminished the prevalence of obesity in the U.S. or had a measurable impact on public health? Despite diverse dietary recommendations and guidelines, the prevalence of obesity in the U.S. continues to rise. Dietary guidelines intended for the general public have long addressed reducing the consumption of sugars and fat. The 1988 Surgeon General's Report on Nutrition and Health ${ }^{51}$ recommended replacing foods high in fat, saturated fat, and cholesterol with vegetables, fruits, and whole grain foods. The 1989 Diet and Health Report of the National Academy of Sciences, ${ }^{52}$ neutral with respect to sugars, recommended increasing intake of carbohydrates to $55 \%$ of total daily calories by doubling the intake of vegetables and fruits.

One problem with high carbohydrate diets is that many people enjoy the taste of fat-rich foods and are reluctant to give them up. ${ }^{53}$ Fats endow foods with their characteristic texture and flavor and play a major role in determining the palatability of the diet. ${ }^{53}$ By contrast, diets composed solely of grains, legumes, pulses, vegetables, and fruit tend to be viewed as bland, monotonous, and unsatisfying. After two decades of high-carbohydrate diets, signs of consumer backlash are already in place, inasmuch as the best-selling diet books of 1996 recommend weight-loss diets that are relatively low in carbohydrate but high in protein and high in fat. ${ }^{54}$ 
The development of new low-fat foods by the food industry has become a public health issue. Among the aims of the Healthy People 2000 Report $^{55}$ was to increase the number of processed foods that were reduced in fat and saturated fat to at least 5,000 brand items. It was specifically noted that such foods should be made available to schools and to low-income families. Because fat is calorically more dense than sugar $(9 \mathrm{kcal} / \mathrm{g}$ as opposed to $4 \mathrm{kcal} / \mathrm{g}$ ), replacing fat in foods offers potentially greater caloric savings to the consumer. Low-energy foods containing macronutrient substitutes offer a way of maintaining a palatable and varied diet, a valuable adjunct to dietary compliance and weight control.

\section{ACKNOWLEDGMENTS}

The author wishes to thank Alisa Levine for her research contributions to this manuscript.

\section{REFERENCES}

1. Flegal, K. M. \& R. P. Troiano. 1996. Shifts in the distribution of body mass index of adults in the US population. Obesity Res. 4(suppl 1): 68S.

2. NAJJAR, M. F. \& M. RoWLAND. 1987. Anthropometric reference data and the prevalence of overweight, United States 1976-80. National Center for Health Statistics, Vital and Health Statistics, 11(238):1-73, DHHS Pub. No. (PHS) 87-1688, US Government Printing Office. Washington, D.C.

3. Gortmaker, S. L., W. H. DietZ, A. M. Sobol \& C. A. Wehler. 1987. Increasing pediatric obesity in the United States. Am. J. Dis. Child. 141: 535.

4. Harlan, W. R., J. R. Landis, K. M. Flegal, C. S. Davis \& M. E. Miller. 1988. Trends in body mass in the United States, 1960-1980. Am. J. Epidemiol. 128: 1065.

5. Flegal, K. M., W. R. Harlan \& J. R. Landis. 1988. Trends in body mass index and skinfold thickness with socioeconomic factors in young adult women. Am. J. Clin. Nutr. 48: 535.

6. NiH Technology Assessment Conference Panel. 1992. Methods for voluntary weight loss and control. Ann. Int. Med. 116: 942-949.

7. LeVy, A. S. \& A. W. HeATON. 1993. Weight control practices of U.S. adults trying to lose weight. Ann. Int. Med. 119: 661-666.

8. Williamson, D. F. 1993. Descriptive epidemiology of body weight and weight change in U.S. adults. Ann. Int. Med. 119: 646-649.

9. Herman, P. C. \& J. Polivy. 1980. Restrained eating. In Obesity. A. J. Stunkard, Ed.: 208-225. H.B. Saunders. Philadelphia.

10. DREwnOwsKi, A. 1993. Low-calorie foods and the prevalence of obesity. In Low-Calorie Foods Handbook. A. M. Altschul, Ed.: 513-534. Marcel Dekker, Inc. New York.

11. Drewnowski, A., D. K. Yee, C. L. Kurth \& D. D. Krahn. 1994. Eating pathology and DSM-IIIR bulimia nervosa: A continuum of behavior. Am. J. Psychiatry 151: 1217-1219.

12. Krahn, D. D., C. L. Kurth, M. A. Demitrack \& A. Drewnowski. 1922. The relationship of dieting severity and bulimic behaviors to alcohol and other drug use in young women. J. Subst. Abuse 4: 341-352.

13. Kurth, C. L., D. D. KRAHN, K. NaIRn \& A. Drewnowski. 1995. The severity of dieting and bingeing behaviors in college women: Interview validation of survey data. J. Psychiatr. Res. 29: 211-225.

14. Garner, G. M., M. P. Olmsted \& J. Polivy. 1983. The eating disorder inventory: A measure of cognitive-behavioral dimensions of anorexia nervosa and bulimia. In An- 
orexia Nervosa: Recent Developments in Research. P. L. Darby, P. E. Garfinkel, D. M. Garner \& D. V. Coscina, Eds.: 173-184. Alan R. Liss. New York.

15. Hoek, H. W. 1993. Review of the epidemiological study of eating disorders. Int. Rev. Psychiatr. 5: 61-74.

16. Drewnowski, A., S. A. Hopkins \& R. L. Kessler. 1988. The prevalence of bulimia nervosa in the US college student population. Am. J. Public Health 78: 1322-1325.

17. American Psychiatric Association. 1994. Diagnostic and Statistical Manual of Mental Disorders, 4th Ed (DSM-IV), APA Press. Washington, D.C.

18. Price, A. R., A. J. Stunkard, R. Ness, T. Wadden, S. Heshka, B. Kanders \& A. CoRmillot. 1990. Childhood-onset (age $<10$ ) obesity has high familial risk. Int. J. Obesity 8: 491 .

19. DREWNOWSKI, A. 1991. Obesity and eating disorders: Cognitive aspects of food preference and food aversion. Bull. Psychon. Soc. 29: 261-264.

20. DrewnowskI, A. 1996. The behavioral phenotype in human obesity. In Why We Eat What We Eat. E. D. Capaldi, Ed.: American Psychological Association. Washington D.C.

21. Roberts, S. B. \& A. S. Greenberg. 1996. The new obesity genes. Nutr. Rev. 54: 41-49.

22. BouCHARD, C. 1988. Inheritance of human fat distribution, fat distribution during growth and later health outcomes. C. Bouchard \& F. E. Johnston, Eds: 103-125 Alan R. Liss. New York.

23. Carroll, M. D., S. Abraham \& C. M. Dresser. 1983. Dietary intake source data: United States, 1976-80, National Center for Health Statistics. Vital and Health Statistics Series 11-No 231, DHHS Pub No (PHS) 83 - 1681. U.S. Govt Printing Office. Washington, DC.

24. Glinsman, W. H., H. Irausquin \& Y. K. Park. 1986. Evaluation of health aspects of sugars contained in carbohydrate sweeteners. J. Nutr. 116(11S): S1-216.

25. Rodin, J. 1981. Psychological factors in obesity. In Recent Advances in Obesity Research III. P. Bjorntorp, M. Cairella \& A. N. Howard, Eds. 106-123. John Libbey. London.

26. Dreon, D. M., B. Frey-Hewitt, N. Elleworth, P. T. Williams, R. B. Terry \& P. D. WoOD. 1988. Dietary carbohydrate-to-fat ratio and obesity in middle-aged men. Am. J. Clin. Nutr. 47: 995.

27. DREwnowski, A. 1987. Sweetness and obesity. In Sweetness. J. Dobbing, Ed. ILSINutrition Foundation Symposium. Springer-Verlag. Berlin.

28. Witherly, S. A., R. M. Pangborn \& J. Stern. 1980. Gustatory responses and eating duration of obese and lean adults. Appetite 1: 53-63.

29. Pangborn, R. M. \& M. Simone. 1958. Body size and sweetness preference. J. Am. Diet. Assoc. 34: 924-928.

30. Pangborn, R. M., M. Simone \& T. A. Nickerson. 1957. The influence of sugar in ice cream: Consumer preferences for vanilla ice cream. Food Technol. 11: 679-682.

31. Drewnowski, A. \& M. R. C. GReENwood. 1983. Cream and sugar: Human preferences for high-fat foods. Physiol. \& Behav. 30: 629-633.

32. Drewnowski, A., J. D. Brunzell, K. Sande, P. H. Iverius \& M. R. C. Greenwood. 1985. Sweet tooth reconsidered: Taste responsiveness in human obesity. Physiol. \& Behav. 35: 617-622.

33. Drewnowski, A., E. E. Shrager, C. Lipsky, E. Stellar \& M. R. C. Greenwood. 1989. Sugar and fat: Sensory and hedonic evaluation of liquid and solid foods. Physiol. \& Behav. 45: 177-183.

34. DrewnowsKi, A. \& M. Schwartz. 1990. Invisible fats: Sensory assessment of sugar/fat mixtures. Appetite 14: 203-217.

35. Drewnowski, A., C. L. KURTH \& J. E. RAHAIM. 1991. Taste preferences in human obesity: Environmental and familial factors. Am. J. Clin. Nutr. 54: 635-641.

36. Monneuse, M., F. Bellisle \& J. Louis-Sylvestre. 1991. Impact of sex and age on sensory evaluation of sugar and fat in dairy products. Physiol. \& Behav. 50: 1111-1117.

37. Bacon, A., J. S. Miles \& S. S. Schiffman. 1994. Effect of race on perception of fat alone and in combination with sugar. Physiol. \& Behav. 55(3): 603-606. 
38. WARwick, Z. \& S. Schiffman. 1990. Sensory evaluations of fat-sucrose and fat-salt mixtures: Relationship to age and weight status. Physiol. \& Behav. 48: 633-636.

39. Crystal, S., C. A. Frye \& R. B. Kanarek. 1995. Taste preferences and sensory perceptions in female varsity swimmers. Appetite 24: 25-36.

40. Martin, C. \& F. Bellisle. 1989. Eating attitudes and taste responses in young ballerinas. Physiol. \& Behav. 46: 223-227.

41. Frye, C. A., S. Crystal, K. D. Ward \& R. B. Kanarek. 1994. Menstrual cycle and dietary restraint influence taste preferences in young women. Physiol. \& Behav. 55(3):561-567.

42. Drewnowski, A., K. A. Halmi, B. Pierce, J. Gibbs \& G. P. Smith. 1987. Taste and eating disorders. Am. J. Clin. Nutr. 46: 442-450.

43. Drewnowski, A., F. Bellisle, P. Aimez \& B. Remy. 1987. Taste and bulimia. Physiol. \& Behav. 41: $621-626$.

44. Simon, Y., F. Bellisle, M. O. Monneuse, B. Samuel-Lajeunesse \& A. Drewnowski. 1993. Taste responsiveness in anorexia nervosa. Br. J. Psychiatry 162: 244-246.

45. Drewnowski, A. \& J. Holden-WILTSE. 1992. Taste responses and food preferences in obese women: Effects of weight cycling. Int. J. Obesity 16: 639-648.

46. Mela, D. J. \& D. A. SACCheTtI. 1991. Sensory preferences for fats: Relationships with diet and body composition. Am. J. Clin. Nutr. 53: 908-915.

47. Fisher, J. O. \& L. L. BirCh. 1995. Fat preferences and fat consumption of 3- to 5-yearold children are related to parental obesity. J. Am. Diet. Assoc. 95(7): 759-764.

48. Meiselman, H. L., D. Waterman \& L. E. Symington. 1974. Armed Forces Food Preferences, Technical Report 75-63-FSL. U.S. Army Natick Development Center. Natick, MA.

49. Drewnowski, A., C. L. Kurth, J. Holden-Wiltse \& J. SaARi. 1992. Food preferences in human obesity: Carbohydrates versus fats. Appetite 18: 207-221.

50. Prentice, A. M., A. E. Black, W. A. Coward, H. L. Davies, G. R. Goldberg, P. R. Murgatroyd, J. Ashford, M. Sawyer \& R. G. Whitehead. 1986. High levels of energy expenditure in obese women. Br. Med. J. 292: 983.

51. U.S. Department of Health and Human Services. 1988. The Surgeon General's Report on Nutrition and Health. DHHS (PHS) Publication no. 88-50210. U.S. Government Printing Office. Washington D.C.

52. National ACAdemy of Sciences. 1989. Committee on Diet and Health. Food and Nutrition Board, Diet and Health. National Academy Press. Washington D.C.

53. Drewnowski, A. 1987. Fats and food texture: Sensory and hedonic evaluations. In Food Texture. H. R. Moskowitz, Ed.: 217-250. Marcel Dekker. New York.

54. Eades, M. R. \& M. D. Eades. 1996. Protein Power. Bantam Books. New York.

55. U.S. Department of Health and Human Services. 1991. Healthy People 2000. U.S. Government Printing Office. Washington, D.C.

56. Drewnowski, A., C. Massien, J. Louis-Sylvestre, J. Fricker, D. Chapelot \& M. APFElbaum. 1994. Comparing the effects of aspartame and sucrose on motivational ratings, taste preferences, and energy intakes. Am. J. Clin. Nutr. 59: 338-345.

57. Drewnowski, A., D. D. Krahn, M. A. Demitrack, K. Nairn \& B. A. Gosnell. 1995. Naloxone, an opiate blocker, reduces the consumption of sweet high-fat foods in obese and lean female binge eaters. Am. J. Clin. Nutr. 61: 1206-1212.

58. Laitinen, J. H., H. M. Tuorila \& M. I. J. Uusitupa. 1991. Changes in hedonic responses to sweet and fat in recently diagnosed non-insulin dependent diabetic patients during diet therapy. Eur. J. Clin. Nutr. 45: 393-400.

59. Drewnowski, A., C. Massien, J. Louis-Sylvestre, J. Fricker, D. Chapelot \& M. Apfelbaum. 1994. The effects of aspartame versus sucrose on motivational ratings, taste preferences, and energy intakes in obese and lean women. Int. J. Obesity 18: 570-578. 